Images du travail, travail des images

Femmes au travail\&nbsp: quelles archives visuelles ?

\title{
Les calibreuses de charbon
}

Bénédicte Rolland-Villemot

\section{(2) OpenEdition}

Journals

Édition électronique

URL : http://journals.openedition.org/itti/773

DOI : $10.4000 /$ itti. 773

Éditeur

Université de Poitiers

\section{Référence électronique}

Bénédicte Rolland-Villemot, "Les calibreuses de charbon », Images du travail, travail des images [En ligne], 6-7 | 2019, mis en ligne le 01 février 2019, consulté le 14 avril 2021. URL : http:// journals.openedition.org/itti/773; DOI : https://doi.org/10.4000/itti.773

Ce document a été généré automatiquement le 14 avril 2021

Images du travail, travail des images 


\title{
Les calibreuses de charbon
}

\author{
Bénédicte Rolland-Villemot
}

Les Calibreuses de charbon dans les mines de la Grande-Combe dans le Gard

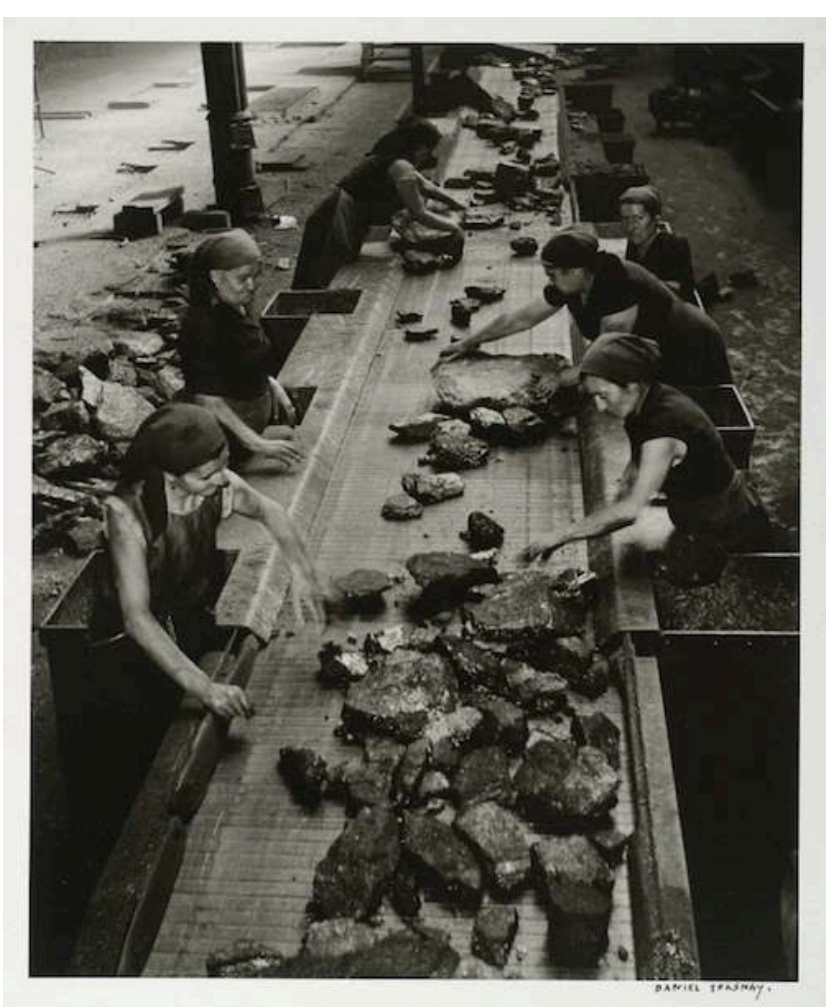

Tirage photographique sur papier baryté dimensions $40 \times 30 \mathrm{~cm}$. Datation vers 1959, lieu de conservation MUCEM (Musée des civilisations de l'Europe et de la Méditerranée) inventaire : 2004.15

1 L'image est extraite de l'ouvrage La Femme en France, de Georges Simenon, publié aux Presses de la Cité à Paris en 1959. Son auteur, Daniel Fresnay, est connu pour son travail pour le célèbre studio de photographie Harcourt spécialisé dans le portrait de célébrités. Il se lance dans une véritable enquête photographique sur les femmes, de la couturière au travail à la femme médecin, en passant par les religieuses et les 
prostituées. L'ouvrage construit, par la photographie, un idéaltype de la femme française dans toutes ses activités.

2 Les "Calibreuses de charbon de la Grande Combe ", montre des femmes travaillant à la mine, avec un fichu sur la tête, en train de trier à mains nues des morceaux de charbon sur un tapis roulant. La nationalisation de cette mine est intervenue en 1946. Les Houillères du bassin des Cévennes modernisent certains puits, jugés rentables, et ferment les autres. Un record est atteint en 1958 avec 3300000 tonnes de minerai produites avec un effectif de 20000 ouvrières et ouvriers sur l'ensemble du bassin houiller. Le code minier n'autorise pas les femmes à travailler au fond. Elles assurent donc des tâches de surface, surtout liés au calibrage et au lavage des morceaux de charbon, vêtues de leurs costumes habituels de paysannes.

3 Au recensement de 1962, les femmes représentent $30 \%$ des effectifs employés dans l'industrie. Pourtant, cette image est une des rares photos du livre à montrer un travail industriel sous les Trente Glorieuses. Même imprégné d'idéologie, ce livre, qui entend construire une représentation de «la » femme, veut en proposer une image moderne, au moment où se renforce l'idée d'émancipation des femmes par le travail.

4 Daniel Fresnay propose ici une héroïsation de la femme dans une mine de charbon. Il donne à voir des femmes dans leur espace de travail en insistant sur la pénibilité de la tâche. Cette archive visuelle, tout en apportant un témoignage sur la réalité du travail ouvrier féminin, nous montre l'apogée des mines de charbon. On croit y voir déjà pointer la menace de la crise industrielle. Les mines de charbon des Cévennes seront parmi les premières à être fermées.

\section{AUTEUR}

\section{BÉNÉDICTE ROLLAND-VILLEMOT}

Conservatrice en chef du patrimoine, Bureau des réseaux territoriaux Sous-direction de la politique des musées, Direction générale des patrimoines, Service des musées de France. Chercheure associée au CH2ST-EA 127, IHMC, Centre d'histoire des techniques de l'Université Panthéon-Sorbonne Paris I Mel : benedicte.rolland-villemot[at]culture.gouv.fr 